\title{
A severe case of tenofovir-associated acute kidney injury requiring hemodialysis in a patient with chronic hepatitis B
}

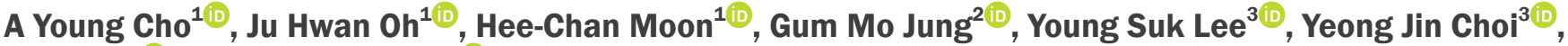 \\ In 0 Sun $^{1}$, Kwang Young Lee ${ }^{1 \text { (iD }}$ \\ 'Division of Nephrology, Department of Internal Medicine, Presbyterian Medical Center, Jeonju, Republic of Korea \\ 2Division of Gastroenterology, Department of Internal Medicine, Presbyterian Medical Center, Jeonju, Republic of Korea \\ ${ }^{3}$ Department of Hospital Pathology, Seoul St. Mary's Hospital, College of Medicine, The Catholic University of Korea, Seoul, Republic of Korea
}

Tenofovir disoproxil fumarate (TDF) is recommended as a first-line monotherapy for chronic hepatitis B (CHB) [1]. Although there are cases of acute kidney injury (AKI) caused by TDF $[2,3]$, there has been no report of a case in a patient who underwent renal replacement therapy in Korea. Here, we describe a severe case of TDF-associated AKI that required hemodialysis in a patient with CHB.

A 55-year-old Korean male with CHB visited the emergency department in our center for evaluation of general weakness and lower extremity edema. He was hepatitis $\mathrm{B}$ e-antigen-negative, and a physician at a local clinic had prescribed TDF $300 \mathrm{mg}$ daily over the previous 18 months. Before starting TDF, the patient's estimated glomerular filtration rate (eGFR) was $58 \mathrm{~mL} / \mathrm{min} / 1.73 \mathrm{~m}^{2}$, whereas the eGFR decreased to $32 \mathrm{~mL} / \mathrm{min} / 1.73 \mathrm{~m}^{2} 3$ months prior to admission. His other medications included losartan $50 \mathrm{mg}$ daily for 1 year for hypertension.

On admission, the patient's pulse measured 76 beats

Received January 30, 2020; Revised June 10, 2020;

Accepted June 10, 2020

Editor: Sungjin Chung, The Catholic University of Korea, Seoul, Republic of Korea

Correspondence: Kwang Young Lee

Department of Internal Medicine, Presbyterian Medical Center, 365 Seowon-ro, Wansan-gu, Jeonju 54987, Republic of Korea. E-mail:kwangpmc@hanmail.net

Copyright (@ 2020 by The Korean Society of Nephrology

(a) This is an open-access article distributed under the terms of the Creative Commons Attribution Non-Commercial License (http://creativecommons. org/licenses/by-nc-nd/4.0/), which permits unrestricted non-commercial use, distribution, and reproduction in any medium, provided the original work is properly cited. per minute, and his blood pressure was 110/80 mmHg. His lower extremities demonstrated grade 2 pretibial pitting edema. Ultrasonography showed normal dimensions of both kidneys (right kidney, $11.0 \mathrm{~cm} \times 5.8 \mathrm{~cm}$; left kidney, $11.5 \mathrm{~cm} \times 5.2 \mathrm{~cm}$ ). Blood urea nitrogen and serum creatinine concentrations were $92 \mathrm{mg} / \mathrm{dL}$ and 15.7 $\mathrm{mg} / \mathrm{dL}$, respectively. Initial arterial blood gas analysis revealed severe metabolic acidosis $\left(\mathrm{pH}=7.190, \mathrm{pCO}_{2}=\right.$ $25.0 \mathrm{mmHg}$, and $\mathrm{HCO}_{3}^{-}=9.5 \mathrm{mmol} / \mathrm{L}$ ) with a high anion gap of 27.5, but the lactate concentration was normal. Other laboratory evaluation revealed the following: serum sodium, $134 \mathrm{mEq} / \mathrm{L}$; urine sodium, $54 \mathrm{mEq} / \mathrm{L}$; urine creatinine, $56.1 \mathrm{mg} / \mathrm{dL}$ (fractional excretion of sodium, $11.3 \%$ ); serum calcium, $8.6 \mathrm{mg} / \mathrm{dL}$; phosphorus, $7.3 \mathrm{mg} /$ $\mathrm{dL}$; potassium, $5.3 \mathrm{mg} / \mathrm{dL}$; serum uric acid, $8.7 \mathrm{mg} / \mathrm{dL}$; urine uric acid, $24.8 \mathrm{mg} / \mathrm{dL}$ (fractional excretion of uric acid, 79.8\%); urinary $\beta 2$-microglobulin, $>20,000 \mu \mathrm{g} / \mathrm{L}$, (reference range: 0 to $300 \mu \mathrm{g} / \mathrm{L}$ ); and urinary anion gap, $33.3 \mathrm{mEq} / \mathrm{L}$. The patient also had proteinuria (urinary protein-to-creatinine ratio, 2.3), hematuria, and glycosuria. Electrophoresis of the serum and urine was negative for monoclonal gammopathy, and his serum alanine aminotransferase was $319 \mathrm{IU} / \mathrm{L}$. Serum albumin was 2.7 $\mathrm{g} / \mathrm{dL}$, and prothrombin time was 1.03 international normalized ratio. Hepatitis B virus DNA was undetectable on admission. His initial urine output was $25 \mathrm{~mL}$ /hour over a period of 6 hours.

Under the clinical impression of oliguric AKI with metabolic acidosis, we initiated hemodialysis and did not perform a biopsy due to the patient's generalized edema on admission. On hospital day 38, percutaneous 


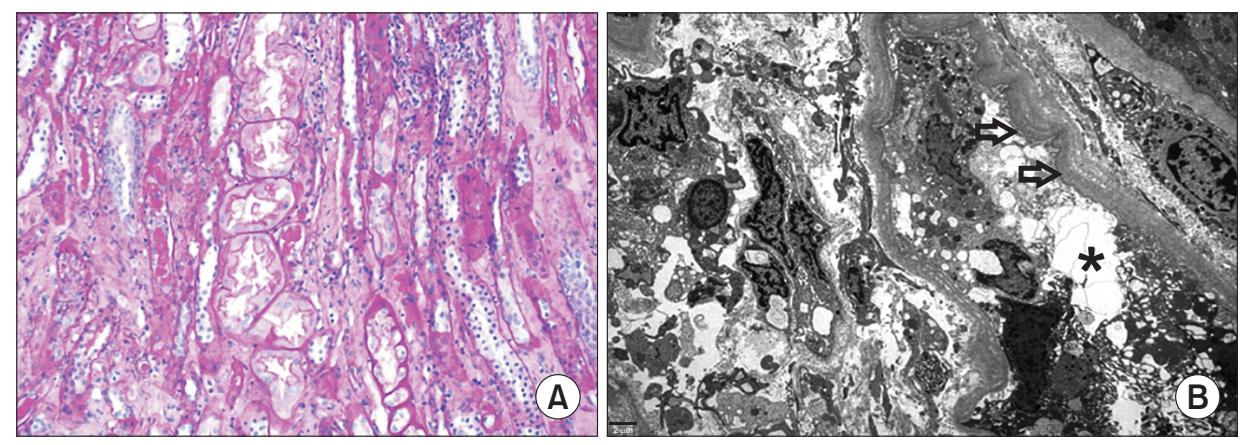

Figure 1. Renal biopsy finding. (A) Light microscopy showed acute and chronic tubulointerstitial nephritis with severe tubular damage, such as loss of the brush border, luminal ectasia, hyaline tubular casts and tubulointerstitial inflammation (hematoxylin and eosin, $\times 200$ magnification). (B) Electron microscopy revealed marked degeneration of the proximal tubular epithelial cells with swelling, vacuolation, ectasia of the endoplasmic reticulum (asterisk), and thickened and multilayered basement membranes (arrows).

renal biopsy was performed to identify the cause of renal dysfunction. Light microscopy findings indicated acute and chronic tubulointerstitial inflammation with a severe degree of acute tubular necrosis, mononuclear cells and neutrophils infiltration. There was global glomerulosclerosis (14\%) without any other glomerular changes (Fig. 1A). Electron microscopy revealed mild effacement of the foot processes, segmental thickening and wrinkling of the glomerular basement membrane, and swollen and edematous endothelial cells. Most tubular structures showed marked degeneration of tubular epithelial cells with swelling, vacuolation, ectasia of the endoplasmic reticulum, and thickened and multilayered basement membranes (Fig. 1B). Immunofluorescence examination revealed negative reactions in the glomeruli, interstitium, and the tubular and vascular structures. Acute and chronic tubulointerstitial nephritis was diagnosed by renal biopsy. Therefore, the patient's medication was switched to entecavir, and renal function showed a gradual subsequent improvement. Hemodialysis was discontinued 1 month after admission. At the 6-month followup visit, the patient's serum creatinine decreased to 2.5 $\mathrm{mg} / \mathrm{dL}$, and his glycosuria and hematuria disappeared.

The incidence of TDF-associated AKI was reported to be $2.9 \%$ [4]. However, to our knowledge, this is the first case of TDF-associated AKI requiring hemodialysis in Korea. In the present case, the patient had several established risk factors for TDF-related renal toxicity, including age $>50$ years, impaired baseline renal function, hypertension, and low body mass index [5]. Based on the recommendation by Venter et al [6], alternate-day dosing of TDF is needed in cases of eGFR $<50 \mathrm{~mL} / \mathrm{min} / 1.73 \mathrm{~m}^{2}$, but the dose of TDF had not been adjusted according to the patient's renal function in our case. Therefore, it is important to either reduce the dose of TDF or switch to another antiviral drug in cases of impaired renal function to prevent severe TDF-associated AKI. The mechanism of TDF-associated AKI has been associated with proximal tubular damage, whereas pan-tubular injury was observed on renal biopsy in our case. We believe that several factors, including hemodynamic changes due to 1 month of hemodialysis, could have affected the histological changes observed in the kidney.

In summary, we reported a severe case of TDF-associated AKI that required hemodialysis in a patient with CHB. In patients who receive TDF for $\mathrm{CHB}$, it is important to monitor renal function and adjust the TDF dose if there is a decrease in renal function.

\section{Conflicts of interest}

All authors have no conflicts of interest to declare.

\section{Authors' contributions}

Gum Mo Jung and In O Sun participated in proposal of idea and designing the study. Hee-Chan Moon participated in the data collection. A Young Cho, Ju Hwan Oh, In O Sun, and Kwang Young Lee wrote the manuscript. Kwang Young Lee participated in the review and supervision. Young Suk Lee and Yeong Jin Choi reviewed the pathological slides and diagnosed kidney diseases as pathologist. All authors read and approved the final manuscript. 


\section{References}

[1] Yuen MF, Lai CL. Treatment of chronic hepatitis B: evolution over two decades. J Gastroenterol Hepatol 2011;26 Suppl 1:138-143.

[2] Hwang HS, Park CW, Song MJ. Tenofovir-associated Fanconi syndrome and nephrotic syndrome in a patient with chronic hepatitis B monoinfection. Hepatology 2015;62:1318-1320.

[3] Cho H, Cho Y, Cho EJ, et al. Tenofovir-associated nephrotoxicity in patients with chronic hepatitis B: two cases. Clin Mol Hepatol 2016;22:286-291.
[4] Ahn SS, Chon YE, Kim BK, et al. Tenofovir disoproxil fumarate monotherapy for nucleos(t)ide-naïve chronic hepatitis B patients in Korea: data from the clinical practice setting in a single-center cohort. Clin Mol Hepatol 2014;20:261266.

[5] Hall AM, Hendry BM, Nitsch D, Connolly JO. Tenofovir-associated kidney toxicity in HIV-infected patients: a review of the evidence. Am J Kidney Dis 2011;57:773-780.

[6] Venter WDF, Fabian J, Feldman C. An overview of tenofovir and renal disease for the HIV-treating clinician. South Afr J HIV Med 2018;19:817. 